\title{
RESISTÊNCIA GENÉTICA INDUZIDA EM PLANTAS CULTIVADAS
}

\author{
Nathália Leal Carvalho \\ Engenheira Agrônoma, Esp. em Agronegócio-luma, Mestre em Agronomia, Produção Vegetal - PPGAgro UFSM, \\ Doutorando no Programa de Pós-Graduação em Agronomia, Produção Vegetal UPF. \\ Faculdade de Agronomia e Medicina Veterinária - FAMV, Campus I, Universidade de Passo Fundo, Caixa Postal 611, \\ CEP 99001-970, Passo Fundo-RS. nathaliiinha@gmail.com
}

\section{RESUMO}

A indução de resistência envolve a ativação de mecanismos de defesa latentes existentes nas plantas em resposta ao tratamento com agentes bióticos ou abióticos. As plantas apresentam sistema de defesa induzível, com a finalidade de economizar energia. Desse modo, a resistência induzida em condições naturais representará custo apenas na presença do patógeno. Porém, plantas que investem seus recursos para se defenderem na ausência de patógenos arcarão com custos que refletirão na produtividade, uma vez que as alterações metabólicas que levam a resistência apresentam custo adaptativo associado, o qual pode pesar mais do que o benefício. $O$ efeito negativo na produtividade ocorre principalmente onde indutores químicos são utilizados repetidas vezes ou em doses mais elevadas. Assim, em alguns casos podemos estar caminhando sobre uma estreita linha entre custo e benefício, onde a cura pode ser ruim tanto quanto a própria doença.

Palavras-chave: tolerância, seletividade patógeno, doença.

\begin{abstract}
Induction of resistance involves the activation of latent existing defense mechanisms in plants in response to treatment with biotic or abiotic agents. The plants have inducible defense system, in order to save energy. Thus, induced resistance under natural conditions would cost only in the presence of the pathogen. However, plants that invest their resources to defend themselves in the absence of pathogens to bear costs that reflect the productivity, since the metabolic changes that lead to adaptive resistance present cost associated, which can weigh more than the benefit. The negative effect on productivity is mainly chemical inducers which are used repeatedly or in higher doses. Thus, in some cases can be walking on a narrow line between cost and benefit, where the cure can be as bad as the disease itself.
\end{abstract}

KEY WORDS: tolerance, selectivity, pathogen, disease.

\section{INTRODUÇÃO}

Qualquer população de plantas na qual os indivíduos constituintes apresentam uma variação geneticamente herdada de tolerância a uma certa medida de controle, aplicada repetida e regularmente, sofrerá mudanças na sua estrutura populacional com o tempo, de tal forma que 
esta população poderá passar de suscetível a resistente. Tal mudança é consequência da seleção natural, conforme proposto por Darwin em 1859.

As doenças infecciosas em plantas acompanham o homem desde os primórdios da agricultura, tendo aumentado sua importância a partir do cultivo em monocultura. Atualmente, em função do incremento populacional e da necessidade crescente de alimento, a despeito das metodologias de controle das doenças, as novas tecnologias de cultivo e o aumento da área cultivada com plantas de interesse alimentar e industrial deverão refletir nos problemas fitopatológicos (Carvalho \& Barcellos, 2012), possivelmente agravando os já existentes e ocasionando o aparecimento de novos (Vanderplank, 1968). Além do controle químico tradicional das doenças depara-se com o surgimento de isolados de patógenos resistentes às substâncias químicas utilizadas, forçando o homem a uma busca contínua por novos agentes químicos. Finalmente, em razão da conscientização cada vez maior da população no tocante a conservação do meio ambiente, a utilização desenfreada de agroquímicos começa a ser repensada e a busca por novas medidas de proteção das plantas contra as doenças começa a ganhar cada vez mais espaço (Camargo \& Bergamin Filho, 1995).

Nesse contexto da proteção de plantas, podemos inserir a indução de resistência que pode ser visualizada como de ocorrência natural durante as interações hospedeiro-patógeno, necessitando apenas da interferência do homem para a possível utilização em escala comercial da mesma (Stadnik, 2000). A resistência induzida envolveria a ativação de mecanismos de resistência latentes nas plantas em resposta ao tratamento prévio com agentes bióticos (p.ex. microrganismos viáveis ou inativados) ou abióticos (p.ex. ácido acetilsalicílico). Essa resposta, a qual pode incluir, por exemplo, o acúmulo de fitoalexinas (compostos tóxicos aos fungos e bactérias), protege a planta contra infecções subsequentes com patógenos. Esses mecanismos de resistência são geneticamente determinados e sua efetividade mostra-se dependente da expressão dos mesmos no momento certo, magnitude adequada e em uma sequência lógica, após o contato do patógeno com o hospedeiro (Stadnik, 2000, Camargo \& Bergamin Filho, 1995, Vanderplank, 1968).

A proteção das plantas através da indução de resistência pode ocorrer em condições de casa-de-vegetação e campo, além de exibir vantagens como: efetividade contra vírus, bactérias, fungos e nematóides; estabilidade devido à ação de diferentes mecanismos de resistência; caráter sistêmico, persistente e natural da proteção; transmissão por enxertia; economia de energia metabólica - a planta permanece em "estado de alerta" e os mecanismos de resistência são ativados na presença do patógeno; presença do potencial genético para resistência em todas as plantas suscetíveis (Vanderplank, 1968). Dentre as diferentes vantagens mencionadas, pensandose no uso potencial do fenômeno no controle de doenças, devemos ressaltar o caráter sistêmico da proteção, onde o tratamento da planta com microrganismos ou compostos químicos, ativa sistemicamente os mecanismos de defesa da planta (Stadnik, 2000). A ocorrência da resistência sistêmica induzida, tanto em monocotiledôneas como em dicotiledôneas, é ilustrada na tabela 1 proposta por Rompf, 1999.

Visto que o fenômeno da resistência sistêmica induzida foi conclusivamente demonstrado na década de 60 e sugerido um papel em potencial para o mesmo na proteção de plantas, a liberação do BHT representa um avanço significativo para as novas estratégias de controle de doenças vegetais. É bastante provável que a resistência induzida contra doenças através de ativadores químicos, como o BHT ou por outros meios, se torne um componente importante dos programas de manejo de doenças, particularmente nos casos onde os métodos atuais de controle mostram-se pouco efetivos, bem como no controle de doenças de pós-colheita envolvendo frutas 
e vegetais (Rezende et al., 2005). Obviamente, um dos resultados dessa nova tecnologia deverá ser a diminuição no uso dos agrotóxicos tradicionais, o que vem de encontro com a preocupação mundial no tocante a preservação do meio ambiente e redução da poluição (Agrios, 2007).

Tabela 1. Ocorrência de resistência sistêmica induzida em algumas culturas proposta por Rompf (1999).

\begin{tabular}{|c|c|c|}
\hline PLANTA & ORGANISMO INDUTOR & PROTEÇÃO SISTÊMICA CONTRA \\
\hline Arroz & Pseudomonas syringae & Magnaporthe grisea \\
\hline \multirow[t]{2}{*}{ Batata } & Phytophthora infestans & Phytophthora infestans \\
\hline & Phytophthora cryptogea & \\
\hline \multirow[t]{4}{*}{ Feijão } & Colletotrichum lindemuthianum & Colletrotrichum lindemuthianum \\
\hline & Colletrotrichum lagenarium & Vírus da necrose do fumo \\
\hline & Uromyces phaseoli & \\
\hline & Pseudomonas fluorescens** & Pseudomonas syringae pv. Phaseolicola \\
\hline \multirow[t]{8}{*}{ Fumo * } & Vírus do mosaico do fumo & Thielaviopsis basicola \\
\hline & Vírus da necrose do fumo & Phytophthora parasítica \\
\hline & Thielaviopsis basicola & Perenosppora tabacina \\
\hline & Perenospora tabacina & Pseudomonas syringae \\
\hline & Pseudomonas syringae & Phytophthora parasítica \\
\hline & Pseudomonas fluorescens & Pseudomonas tabaci \\
\hline & Strain $\mathrm{CHAO}$ & Vírus do mosaico do fumo \\
\hline & & Vírus da necrose do fumo \\
\hline Melancia & Fusarium oxysporum f.sp.cucumerinum & Colletotrichum lagenarium \\
\hline Melão & Colletotrichum lagenarium & Colletotrichum lagenarium \\
\hline \multirow[t]{8}{*}{ Pepino* } & Colletotrichum lagenarium & Colletotrichum lagenarium \\
\hline & Pseudomonas cubensis & Cladosporium cucumerinum \\
\hline & Pseudomonas lacrymans & Fusarium oxysporum \\
\hline & Vírus da necrose do fumo & Pseudomonas lachrymans \\
\hline & & Sphaerotheca fuliginea \\
\hline & & Vírus da necrose do fumo \\
\hline & Pseudomonas putida** & Colletotrichum orbuculare \\
\hline & Serratia mascerans** & \\
\hline \multirow[t]{2}{*}{ Soja } & Colletotrichum lagenarium & Colletotrichum truncatum \\
\hline & Colletotrichum truncatum & \\
\hline Tomate & Phytophthora infestans & Phytophthora infestans \\
\hline
\end{tabular}

* Experimentos conduzidos em campo;

** Alguns autores denominam a resposta de proteção por esses indutores de resistência sistêmica induzida, visto o indutor se localizar na rizosfera, não originar nenhum tipo de sintoma e induzir resistência no caule e nas folhas.

\section{RESISTÊNCIA GENÉTICA INDUZIDA EM PLANTAS CULTIVADAS}

O controle de doenças torna-se mais efetivo, econômico e ecológico, quando se utilizam diversas táticas de forma integrada. Dentre estas, a utilização da resistência genética representa um dos métodos de controle mais eficientes, de fácil acesso aos produtores e econômico, reduzindo, de forma expressiva, os prejuízos com a doença e custos de produção (Rezende et al., 2005). Além disto, a resistência genética de plantas é a forma principal de controle das murchas vasculares, ferrugens, carvões, oídios e viroses, permitindo a produção em níveis aceitáveis, sem a aplicação de outros métodos de controle (Agrios, 2007; Camargo \& Bergamin Filho, 1995). 
Atualmente a produção agrícola mundial é dirigida para uma maior especialização nas culturas, monocultura e globalização da produção e mercado. Estes fatores promovem, respectivamente, maior suscetibilidade a doenças, variação nas populações dos patógenos e consequente perda da resistência e, ainda, disseminação de agentes causais, que não são restringidos pelos serviços de quarentena (Rezende et al., 2005). Nesse sistema de produção, quantidades massivas de fungicidas são utilizadas no controle de doenças, interferindo no ambiente e causando danos significativos a saúde das populações consumidoras. Assim, a utilização de métodos alternativos de controle de doenças de plantas constitui grande desafio para a agricultura moderna, destacando-se entre outros o uso da resistência genética de plantas aos patógenos (Tuzun \& Kuc, 1991).

Para contornar problemas de doença adotamos principalmente a aplicação de fungicidas (Rezende et al., 2005). Contudo, o uso intensivo destes fungicidas pode provocar resistência do patógeno aos mesmos, bem como afetar a saúde humana, tanto do consumidor, como a dos profissionais envolvidos nos processos de produção e provocar efeitos negativos sobre o meio ambiente (Tuzun \& Kuc, 1991).

Uma das alternativas ao controle químico, o emprego da resistência genética tem sido uma das práticas mais eficientes dentro do manejo integrado (Rezende et al., 2005). No entanto, um programa de melhoramento genético é oneroso e demorado, nem sempre respondendo rapidamente à necessidade da agricultura (Cavalcanti et al., 2005). Contudo, uma alternativa de fácil manejo e baixo custo é a resistência induzida, que consiste no aumento do nível de resistência da planta por meio da utilização de agentes externos (indutores), sem qualquer alteração do genoma da planta (Stadnik, 2000).

A utilização de cultivares com quaisquer tipos de resistência deve ser estimulada, face às vantagens que oferece em relação ao meio-ambiente, limitação do uso de fungicidas e redução da população dos patógenos a nível local e regional. Atualmente existem ainda poucos estudos de resistência genética a doenças (Rezende et al., 2005).

Além do uso de agentes bióticos para a indução de resistência sistêmica, vários compostos químicos (p.ex. ácido salicílico e dicloroisonicotínico [INA]), têm sido utilizados com a mesma finalidade em várias plantas. Nesse contexto, recentemente um novo composto, um éster S-metil do ácido benzo $(1,2,3)$ tiadiazol-7 carbotióico (conhecido por Bion, BTH ou CGA 245704) foi produzido e liberado comercialmente na Alemanha, como o primeiro ativador de defesa vegetal ("plant defense activator") (Rezende et al., 2005). O BTH mostrou-se particularmente efetivo em plantas monocotiledôneas, sendo que uma única aplicação em trigo (geralmente $60 \mathrm{~g} /$ hectare) resultava em proteção significativa das plantas por várias semanas contra Erysiphe graminis (causador do oídio), além de suprimir a mancha de folha e ferrugem causada por Septoria sp. e Pucinia sp., respectivamente. Similarmente, uma única aplicação do BHT em arroz propiciava uma proteção bastante longa contra Pyricularia oryzae, agente da brusone (Cavalcanti et al., 2005).

$O$ ativador vegetal também induziu resistência em plantas dicotiledôneas como fumo, pepino, tomate e feijão, porém várias aplicações foram necessárias para reduções significativas nos sintomas. Da mesma forma que outros compostos químicos, como o INA, o BTH é facilmente translocado no interior da planta e não exibe efeito antimicrobiano direto. Aparentemente, o BTH estimula as mesmas respostas de defesa observadas após o tratamento das plantas com INA, sendo provavelmente um outro análogo funcional do ácido salicílico (Van Loon et al., 1998, Agrios, 2007). 
Rev. Elet. em Gestão, Educação e Tecnologia Ambiental (e-ISSN: 2236-1170)

\section{TIPOS DE RESISTÊNCIA GENÉTICA}

A resistência é uma característica genética da planta hospedeira que pode impedir ou reduzir a incidência e/ou severidade da doença (Carvalho \& Barcellos, 2012). É obtida a partir de programas de melhoramento visando à incorporação de genes de resistência ou pela aplicação de indutores biológicos ou químicos que ativam sistemas de defesa na planta (Camargo \& Benjamin Filho, 1995).

A resistência de plantas foi classificada por Vanderplank (1968), como vertical (RV) e horizontal $(\mathrm{RH})$ em função da interação diferencial significativa entre raças do patógeno e cultivares do hospedeiro. Conceitualmente, a RV verifica-se quando ocorre interação diferencial significativa entre raças e cultivares, sendo a resistência efetiva contra algumas raças e não a outras. Este tipo de resistência é conhecido como raça-específica, oligogênica, resistência completa ou qualitativa (Cavalcanti et al., 2005). Geralmente tem expressão caracterizada quando não ocorrem sintomas da doença, como por exemplo na cultivar Diamante 22 de D. alata, resistente a antracnose na Colômbia. Em virtude de constantemente ocorrerem mudanças genéticas para patogenicidade nas populações dos patógeno, os genes que conferem RV podem não serem efetivos em todas regiões e, portanto, cultivares completamente resistentes em determinado local podem ser suscetíveis em outro (Vanderplank, 1968; Rezende et al., 2005). Por outro lado, a RH caracteriza-se por não exibir interação diferencial entre raças e cultivares, sendo efetiva contra todas as raças do patógeno. É denominada raça não-específica, parcial, poligênica, resistência de campo ou de planta adulta e qualitativa. A RH caracteriza-se pela proteção incompleta, onde a infecção ocorre, no entanto progride lentamente, resultando em danos as vezes significativos na produção (Camargo \& Benjamin Filho, 1995; Agrios, 2007).

Durante o processo evolucionário, as plantas adquiriram uma sofisticada estratégia defensiva para 'perceber' os ataques de patógenos e insetos, traduzindo essa percepção em uma resposta apropriada e de forma adaptativa. A imunidade inata da planta é baseada surpreendemente na resposta complexa que é altamente flexível nas suas capacidades de reconhecer e responder aos mais diversos invasores (Camargo \& Benjamin Filho, 1995).

No processo evolutivo, as plantas desenvolveram mecanismos de defesa que somente são ativados em resposta a infecção por patógenos ou tratamento com determinados compostos químicos, naturais ou sintéticos, denominados elicitores (Cavalcanti et al., 2005). A resistência, neste caso, é classificada como induzida. Este tipo de resistência pode ocorrer nos tecidos próximos a reação de necrose, causada pela infecção do patógeno ou tratamento químico, sendo chamada de resistência local adquirida (Vanderplank, 1968; Rezende et al., 2005). Em seguida a este processo, por meio da transmissão de sinais bioquímicos, outras partes da planta são induzidas a produzir substâncias de defesa, caracterizando a resistência sistêmica adquirida (Agrios, 2007).

A resistência sistêmica adquirida (RSA) pode ser distinguida de outros tipos de resistência pela expressão contra um largo espectro de patógenos. Em fumo, a ativação da RSA resultou na redução significativa de sintomas causados pelos fungos Phytophthora parasítica, Cercospora nicotinae e Peronospora tabacina, os vírus do mosaico do fumo (TMV) e da necrose do fumo (TNV) e as bactérias Pseudomonas syringae pv tabaci e Erwinia carotovora (Tuzun \& Kuc, 1991). Os principais mecanismos de defesa envolvidos na RSA são a lignificação da parede celular e produção de proteínas relacionadas com a patogênese, como por exemplo as quitinases e $\beta$-1-3glucanases (Sticher et al.,1997). 
Rev. Elet. em Gestão, Educação e Tecnologia Ambiental (e-ISSN: 2236-1170)

A indução da RSA constitui um importante método alternativo de controle de doenças de plantas e, em face da praticidade de uso no campo, vários produtos químicos têm sido pesquisados quanto ao efeito indutor em pulverizações foliares. No inhame, Rompf (1999) verificou a produção de diversas quitinases utilizando elicitores bióticos (Fusarium oxysporum autoclavado) e abióticos (etileno, quitina e quitosana) aplicados em calos de $D$. alata. Em culturas de células de $D$. bulbifera (inhame aéreo), demonstrou a expressão de uma PR-proteína de defesa pela elicitação com o fungo Colletotrichum gloeosporioides (Rompf, 1999). O estudo da genética de fatores envolvidos na regulação da RSA tem possibilitado, em alguns patossistemas, a obtenção de plantas transgênicas com acentuada expressão da RSA, tornando bastante promissor o uso deste tipo de resistência no controle de doenças de plantas (Cao et al.,1998).

\section{RESISTÊNCIA SISTÊMICA INDUZIDA POR RIZOBACTÉRIA}

Estirpes não patogênicas, bactérias colonizadoras da rizosfera são designadas como rizobactérias promotoras do crescimento de plantas (PGPR), porque elas podem estimular o crescimento de plantas (Kloepper et al., 1980). O crescimento resulta principalmente da repressão de patógenos de solo e outros microorganismos prejudiciais (Schippers et al., 1987), mas há também relatos do efeito direto no crescimento (Van Peer \& Schippers, 1989). As bactérias fluorescentes, Pseudomonas spp., estão entre as mais efetivas PGPR's e tem sido mostrado que são responsáveis pela redução de doenças em solos naturalmente não infestados (Raaijmaker \& Weller, 1988).

A atividade do controle biológico de estirpes selecionadas de Pseudomonas spp. é efetiva sob certas condições de campo (Tuzun \& Kuc, 1991; Cao et al., 1998) e em casas de vegetação comerciais (Leeman et al., 1995), e podem ser resultantes da competição por nutrientes, competição por ferro com sideróforos e antibiose (Bakker et al., 1991).

\section{DIFERENÇA NA EFETIVIDADE DE ISR E SAR}

Um dos paralelos entre a ISR induzida por rizobactéria e a SAR induzida por patógeno é que ambos tipos de resistência induzida são efetivas contra um amplo espectro de patógenos de plantas (Tuzun \& Kuc, 1991; Van Loon et al., 1998). Para comparar o espectro de efetividade de ISR e SAR, um grande número de patógenos (vírus, bactéria, fungos e oomicetos) de Arabidopsis foi testado. A ISR e a SAR em WCS417r foram induzidas por uma estirpe avirulenta do patógeno Pst DC3000, sendo efetivo contra a mancha bacteriana e a podridão negra, causadas, respectivamente, pelas bactérias Pst DC3000 e X. campetris pv. armoraciae (Pieterse et al., 1998; Ton et al., 2002). A murcha de Fusarium, causada pelo fungo $F$. oxysporum f.sp. raphani também foi afetada por respostas defensivas ativadas durante ISR e SAR (Pieterse et al., 1998; Van Wees et al, 1999). Além disso, a doença causada por $P$. parasitica, o míldio, foi inibida em ambos os casos, apesar de que a SAR foi significativamente mais efetiva do que ISR (Ton et al., 2002). Além desses efeitos similares, existem algumas diferenças claras. Por exemplo, plantas expressando ISR demonstram um aumento na resistência contra infecção pelo fungo $A$. brassicicola, enquanto SAR não é efetiva contra esse patógeno (Tuzun \& Kuc, 1991). Contrariamente, a expressão de SAR inibe a multiplicação do vírus do crestamento do nabo e fortemente reduz os sintomas causados por esse vírus, enquanto ISR não tem efeito nenhum (Ton el. al., 2002). Desse modo, o espectro de 
Rev. Elet. em Gestão, Educação e Tecnologia Ambiental (e-ISSN: 2236-1170)

efetividade de ISR e SAR sobrepõe-se parcialmente, mas também diverge, sugerindo que as respostas defensivas ativadas durante os dois tipos de resistência induzida são no mínimo, diferentes (Pieterse et al., 1998).

\section{PAPEL DO ÁCIDO JASMÔNICO (AJ) E DO ETILENO (ET) NA ISR}

Em Arabidopsis, tanto o AJ quanto o ET, ativam um grupo de genes relacionados com defesa e quando aplicados de maneira exógena, conferem resistência contra Pst DC3000 (Pieterse et al., 1998; Van Wees et al., 1999). Com intuito de investigar se ISR é associada com mudanças na expressão gênica de AJ e ET, Van Wees et al. (1999) monitoram a expressão de um grupo de genes bem caracterizados relacionados com AJ e/ou ET (por exemplo, LOX1, LOX2, VSP, PDF1.2, $H E L, C H I R-B$ e PAL1) na planta modelo Arabidopsis expressando ISR por WCS417r. Nenhum desses genes testados teve suas expressões alteradas na planta indutora, nem localmente nas raízes ou sistematicamente nas folhas. Isso sugere que a resistência alcançada não foi associada com maiores mudanças nos níveis de AJ e ET (Van Wess et al., 1999). De fato, análises local e sistêmica dos níveis de AJ e ET mostraram que ISR por WCS417r não está associada com a produção dessas moléculas sinais. Esse resultado sugere que a dependência de AJ e ET a ISR é baseada no aumento da sensibilidade a esses hormônios, do que a um aumento na produção deles (Pieterse et al., 1998).

Se a dependência de ISR a AJ e ET é baseada em um aumento na sensibilidade a essas moléculas, plantas expressando ISR seriam capazes de reagir mais rápido e de modo mais potente a produção de AJ e ET quando infectadas por patógenos. Essa hipótese é ancorada no resultado de que a expressão de alguns genes de Arabidopsis induzidos por AJ e ET (VSP, PDF1.2, HEL) é significativamente aumentada em folhas expressando ISR, depois serem inoculadas com Pst DC3000 ou depois da aplicação exógena de MeJA ou do percussor do ET, o ACC, quando comparadas com plantas controle (Van Wees et al., 1999). Esses resultados sugerem que ISR em Arabidopsis é associada com uma expressão inicial de um grupo de genes que respondem ao AJ. A expressão de genes de defesa, que leva a uma rápida ou maior nível de expressão depois da inoculação, aparece como uma ação comum nos diferentes tipos de resistência induzida (Conrath \& Pieterse, 2002). Isso pode explicar, por um lado, a aparente falta de mudanças na expressão gênica em tecidos induzidos na ausência do patógeno desafiador, enquanto por outro lado, a planta é capaz de reagir mais eficientemente contra um patógeno invasor (Conrath \& Pieterse, 2002).

\section{RESISTÊNCIA INDUZIDA EXPRESSA COM AUMENTO DA RESISTÊNCIA BASAL}

Diferente de seus papéis na resistência sistêmica induzida, as moléculas sinais de defesa, AS, AJ, e ET são descritas estarem envolvidas na regulação primária de resposta de defesa. Evidências para o papel do AS, AJ e ET em resistência basal vêm de análises genéticas de plantas mutantes de Arabidopsis e transgênicas que são afetadas na biosíntese ou percepção desses compostos (Van Wees et al., 1999). Em muitos casos, os genótipos afetados em sinalização de AS, AJ ou ET, demonstraram um aumento na susceptibilidade ao ataque do patógeno ou inseto (Camargo \& Bergamin Filho, 1995). AS, AJ e ET estão envolvidos em diferentes magnitudes na resistência basal contra patogênicos específicos. Por exemplo, a resistência basal em Arabidopsis 
Rev. Elet. em Gestão, Educação e Tecnologia Ambiental (e-ISSN: 2236-1170)

contra o oomiceto $P$. parasitica e o vírus do crestamento do nabo, parece ser controlada predominantemente por uma rota dependente de AS (Conrath \& Pieterse, 2002). Somente plantas NahG não acumuladoras de AS, demonstraram um aumento na susceptibilidade a esses patógenos (Coelho, 2003). Contrariamente, a resistência basal contra os fungos patogênicos $A$. brassicicola e B. cinerea é reduzida somente em mutantes insensíveis ao AJ e ET, e não em plantas NahG (Ton et al., 2002). Interessantemente, a resistência basal contra as bactérias Pst DC3000 e $X$. campestris pv. armoraciae é afetada em plantas NahG e em mutantes responsivos a AJ e ET (Pieterse et al., 1998; Ton et al., 2002), sugerindo que a resistência basal contra esse patógenos é controlada por uma combinação de ações do AS, AJ e ET (Conrath \& Pieterse, 2002).

Comparações de efetividade da SAR dependente de AS e ISR dependente de AJ/ET contra esses diferentes patógenos de Arabidopsis, revelaram que SAR é predominantemente eficaz contra patógenos que em plantas não induzidas são resistentes através do mecanismo de resistência basal dependente de AS, enquanto que a ISR é predominantemente efetiva contra patógenos que nas plantas não induzidas são resistentes através das respostas de resistência basal dependente de AJ e ET (Ton et al., 2002). Desse modo, SAR parece constituir-se em um aumento das defesas dependentes de AS, enquanto ISR parece ser baseada em um aumento da defesas dependentes de AJ e ET (Coelho, 2003).

\section{RESISTÊNCIA GENÉTICA EM RELAÇÃO ÀS PRINCIPAIS DOENÇAS DO INHAME}

Através da hibridização, o IITA tem desenvolvido novos genótipos das espécies mais cultivadas de inhame e disponibilizado estes materiais para as diversas regiões produtoras no mundo (Conrath \& Pieterse, 2002). Em campos de multiplicação na Nigéria, os clones são avaliados para reação a algumas doenças de parte aérea, tais como: antracnose; manchas foliares e viroses. Apesar da disponibilidade de material genético, verifica-se a realização de poucos estudos, a nível mundial, visando a utilização da resistência genética no controle de doenças do inhame. A maioria dos trabalhos vem sendo desenvolvidos em relação a antracnose, mosaico e meloidoginose (Coelho, 2003).

\section{USO DO SILÍCIO COMO INDUTOR DE RESISTÊNCIA}

O silício tem sido relatado como um dos elementos associados à indução da resistência em plantas e sua absorção pode trazer aumento dessa resistência, principalmente para culturas que o acumulam (Mauad et al., 2003). Pesquisas realizadas com diversas culturas confirmaram o potencial do silício na redução da intensidade e severidade de doenças (Menzies et al., 1991; Datnoff et al., 1997). Plantas de arroz (Oryza sativa L.), por exemplo, cultivadas com doses crescentes desse elemento tiveram a severidade da queima-das-bainhas (Rhizoctonia solani Kühn) reduzida (Rodrigues et al., 2002). No entanto, para o mamoeiro os efeitos do silício sobre as doenças ainda não foram testadas.

O mecanismo pelo qual o silício afeta o desenvolvimento das doenças em plantas é possivelmente resultado da ação deste elemento no tecido do hospedeiro, proporcionando impedimento físico e um maior acúmulo de compostos fenólicos e lignina no local da injúria (Chérif et al., 1992). Esta função estrutural proporciona mudanças anatômicas nos tecidos, como células epidérmicas com a parede celular mais espessa devido à deposição de sílica nas mesmas 
Rev. Elet. em Gestão, Educação e Tecnologia Ambiental (e-ISSN: 2236-1170)

(Blaich \& Grundh Fer, 1998), favorecendo a melhor arquitetura das plantas, além de aumentar a capacidade fotossintética e resistência às doenças (Menzies et al., 1991).

Dentre as fontes de silício, o silicato de cálcio (CaSiO3) é a forma mais empregada na maioria dos produtos comerciais (Rodrigues et al., 2002). Entre os produtos comercializados têmse a argila silicatada, cujo, nome comercial é Rocksil ${ }^{\circledR}$. Um outro exemplo de produto comercial é o fertilizante organomineral, cujo nome comercial é Ergofito ${ }^{\circledR}$, que atua proporcionando uma rápida assimilação de nutrientes disponíveis, aumentando a produção de massa vegetal, fato que pode tornar a planta resistente a patógenos (Rodrigues et al., 2002).

\section{COMBINANDO ISR E SAR PARA MELHORAR O CONTROLE DE DOENÇAS DE PLANTAS}

As doenças de plantas são responsáveis por altas perdas na agricultura. Os métodos convencionais de controle são baseados na aplicação de agentes químicos e melhoramento genético visando à resistência (Pieterse et al., 1998; Van Wees et al, 1999). O uso de agentes químicos e sua presença no solo são altamente perigosos ao meio ambiente, especialmente quando esses químicos são aplicados repetitivamente de modo exagerado no solo para o controle de patógenos. Métodos clássicos de melhoramento dependem da disponibilidade de genes de resistência, os quais frequentemente tem durabilidade curta (Coelho, 2003). Além disso, essas duas estratégias de controle de doenças estão direcionadas contra um ou um grupo pequeno de patógenos. Resistência induzida é uma forma alternativa atrativa para a proteção de plantas, sendo baseada na ativação de mecanismos de resistência existentes na planta e no efeito contra um amplo espectro de patógenos de plantas (Van Loon et al., 1998). Desse modo, o conhecimento detalhado dos mecanismos moleculares da resistência induzida será importante no desenvolvimento de ações biológicas, duráveis e não danosas ao meio ambiente para proteção das culturas (Camargo \& Bergamin Filho, 1995).

A ativação simultânea de ISR e SAR resulta num nível maior de proteção induzida contra $P$. syringae pv. tomato (Van Wees et al., 2000). Isso indica que a rota de ISR dependente de AJ e ET e SAR dependente de AS agem de modo independente e aditivo no nível de proteção contra esse patógeno em particular. Além disso, evidências que ISR e SAR conferem proteção diferenciada contra os mais diferentes tipos de patógenos (Ton et al., 2002). Então a combinação desses dois tipos de resistência induzida pode proteger a planta contra um espectro complementar de patógenos, e pode até resultar num nível aditivo de proteção induzida contra patógenos, cuja resistência do respectivo hospedeiro se processe através das rotas dependentes de AJ/ET e AS (Coelho, 2003).

O controle biológico de plantas está ainda engatinhando, devido ao nível de proteção e sua consistência serem gerais e não suficientes para competir com os métodos convencionais de controle de doenças (Carvalho \& Barcellos, 2012). Uma importante ação para melhorar a eficácia e consistência do controle biológico contra patógenos de solo seria aplicar combinações de microorganismos antagônicos com diferentes meios de ação (De Boer et al., 1999). Além disso, a combinação de ISR e SAR confere proteção contra um grande número de patógenos e um aumento dos níveis de proteção contra patógenos bacterianos específicos (Van Wees et al., 1999), nos oferece um grande potencial para integrar ambas formas de proteção de resistência induzida em futuras práticas agronômicas (Camargo \& Bergamin Filho, 1995). 


\section{CONCLUSÕES}

As plantas desenvolveram mecanismos de defesa que somente são ativados em resposta a infeç̧ão por patógenos ou tratamento com determinados compostos químicos (naturais ou sintéticos);

Resistência induzida pode ocorrer nos tecidos próximos a reação de necrose, causada pela infecção do patógeno ou tratamento químico, sendo chamada de resistência local adquirida;

Resistência sistêmica adquirida é caracterizada pela transmissão de sinais bioquímicos, e outras partes da planta são induzidas a produzir substâncias de defesa;

Ambas ISR e SAR são ferramentas importantes no controle de doenças de plantas e são efetivas contra um amplo espectro de patógenos de plantas;

SAR constitui-se em um aumento das defesas dependentes de AS, enquanto ISR baseia-se em um aumento da defesas dependentes de AJ e ET;

A ativação simultânea de ISR e SAR resulta num nível maior de proteção;

Resistência induzida é uma forma alternativa atrativa para a proteção de plantas;

Pesquisas com a resistência induzida devem ser estimuladas e trabalhos sobre variabilidade dos patógenos e herança da resistência devem ser incentivados a fim de que o controle através da resistência genética seja mais efetivo.

\section{REFERÊNCIAS}

AGRIOS, G. N. Plant pathology. 4 th ed. New York: Academic Press, 635 p. 2007.

BAKKER, P.A.H.M.; VAN PEER, R; SCHIPPERS, B. Suppression of soil borne plant pathogens by fluorescent pseudomonads: mechanisms and prospects. In: TEMPEL, A. (Ed.). Biotic interactions and soil-borne diseases. Amsterdam, The Netherlands: Elsevier Scientific Publishers, p.217-30. 1991.

BLAICH, R; GRUNDHÖFER, H. Silicate incrusts induced by powdery mildew in cell walls of diferent plant species. Zeitschift fur Pflanzenkrankheiten und Pflanzenschutz, v.105, p. 114-120. 1998.

CAMARGO, L. E. A.; BERGAMIN FILHO, A. Controle genético. In: BERGAMIN FILHO, A.; KIMATI, H.; AMORIM, L. (Eds). Manual de fitopatologia: princípios e conceitos, 3 ed. São Paulo, Agronômica Ceres, p. 729758.1995.

CAO, H.; XIN, L.; DONG, X. Generation of broad-spectrum disease resistance by overexpression of an essential regulatory gene in systemic acquired resistance. Proc. Nat. Acad. Science, v. 95, p. 65316536.1998.

CARVALHO, N.L.; BARCELLOS, A.L. Adoção do manejo integrado de pragas baseado na percepção e educação ambiental .Revista Eletrônica em Gestão, Educação e Tecnologia Ambiental - REGET/UFSM v(5), $n^{\circ} 5$, p. 749 - 766, 2012.

CAVALCANTI, L.S.; PIERO, R.M.; CIA, P.; PASCHOALATI, S.F.; RESENDE, M.L.V.; ROMEIRO, R.S. Indução de resistência a patógenos e insetos. Piracicaba: FEALQ. 263 p. 2005.

CONRATH, U.; PIETERSE, C.M.J., Mauch-Mani, B. Priming in plant-pathogen interactions. Trends Plant Sci. 7:210-6. 2002. 
COELHO, R. S. B.; Resistência Genética a Doenças na Cultura do Inhame (Dioscorea spp.); Empresa Pernambucana de Pesquisa Agropecuária-IPA, Av. General San Martin, 1371, Bongi, Recife - PE. 2003.

CHÉRIF, M.; MENZIES, J.G.; BENHAMOU, N.; BÉLANGER, R.R. Studies of silicon distribution in wounded and Pythium ultimum infected cucumber plants. Physiological and Molecular Plant Pathology, v.41, p. 371-385. 1992.

DARWIN, C. On the Origin of Species by Means of Natural Selection, or The Preservation of Favoured Races in the Struggle for Life. 1859.

DATNOFF, L.E., DEREN, C.W.; SNYDER, G.H. Silicon fertilization for disease management of rice in Florida. Crop Protection, v.16, p. 525-531. 1997.

DE BOER, M.; VAN DER SLUIS, I.; VAN LOON, L.C., BAKKER, P.A.H.M. Combining fluorescent Pseudomonas spp. strains to enhance suppression of fusarium wilt of radish. Eur. J. Plant Pathol. 105:201-10. 1999.

KLOEPPER, J.W.; LEONG, J.; TEINTZE, M.; SCHROTH, M.N. Enhanced plant growth by siderophores produced by plant growthpromoting rhizobacteria. Nature 286:885-6. 1980.

LEEMAN, M.; VAN PELT, J.A.; HENDRICKX, M.J.; SCHEFFER, R.J.; BAKKER, P.A.H.M.,

AND SCHIPPERS, B. Biocontrol of fusarium wilt of radish in commercial greenhouse trials by seed treatment with Pseudomonas fluorescens WCS374. Phytopathology 85:1301-5.LUCAS, A. J. Plant pathology and plant pathogens, 3 th ed. London, Blackwell Science Ltd., 274 p. 1998.

MAUAD, M.; GRASSI FILHO, H.; CRUSCIOL, C.A.C.; CORRÊA, J.C. Teores de silício no solo e na planta de arroz de terras altas com diferentes doses de adubação silicatada e nitrogenada. Revista Brasileira de Ciência do Solo, v.27, p. 867-873. 2003.

MENZIES, J.G.; EHRET, D.L.; GLASS, A.D.M.; HELMER, T.; KOCH, C.; SEYWERD, F. Effects of soluble silicon on the parasitic fitness of Sphaerotheca fuliginea on Cucumis sativus. Phytopathology, v.81, p. 84-88. 1991.

PIETERSE, C.M.J.; VAN WEES, S.C.M.; HOFFLAND, E.; VAN PELT, J.A., VAN LOON, L.C. Systemic resistance in Arabidopsis induced by biocontrol bacteria is independent of salicylic acid accumulation and pathogenesisrelated gene expression. Plant Cell 8:1225-37. 1998.

RAAIJMAKERS, J.M., WELLER, D.M.. Natural plant protection by 2,4-diacetylphloroglucinol-producing Pseudomonas spp. in take-all decline soils. Mol. Plant-Microbe Interact. 11:144-52. 1998.

REZENDE, J.A.M.; MARTINS, M.C. Doenças do mamoeiro. In: KIMATI, H., AMORIM, L.; REZENDE, J.A.M.; BERGAMIM FILHO, A.; CAMARGO, L.E.A. (Ed). Manual de Fitopatologia. Doença das plantas cultivadas. São Paulo: v. 2, p. 435-443. 2005.

RODRIGUES, F.A.; VALE, F.X.R.; KORNDÖRFER, G.H.; PRABHU, A.; DATNOFF, L.E.; OLIVEIRA, A.M.A.; ZAMBOLIM, L. Influence of silicon on sheath blight of rice in Brasil. Crop Protection, v.22, p. 23-29. 2002.

ROMPF, R.. An elicitor-induced CDNA from aerial (Dioscorea bulbiferaL.) encodes a pathogenesis-related type 4 protein. Plant Cell Reports, v. 18, p.601-608. 1999.

SCHIPPERS, B.; BAKKER, A.W.; BAKKER, P.A.H.M. Interactions of deleterious and beneficial rhizosphere micoorganisms and the effect of cropping practices. Annu. Rev. Phytopathol. 115:339-58. 1987. 
STADNIK, M. Indução de resistência a oídios. In: CONGRESSO PAULISTA DE FITOPATOLOGIA, Campinas. Anais do Congresso Paulista de Fitopatologia, v. 23, p. 176-181. 2000.

StICHER, L.; MAUCH-MANI, B.; METRAUX, J. P. Systemic Acquired Resistance. Ann. Rev. Phytopathology, v.35, p. 235-270, 1997.

TON, J.; VAN PELT, J.A.; VAN LOON, L.C., PIETERSE, C.M.J. Differential effectiveness of salicylate-dependent and jasmonate/ethylenedependent induced resistance in Arabidopsis. Mol. Plant-Microbe Interact. 15:2734. 2002.

TUZUN, S.; KUC, J. Plant immunization: an alternative to pesticides for control of plant diseases in the greenhouse and field. Technical Bulletin-Food and Fertilizer Technology Center, v.124, 11 p. 1991.

VAN LOON, L.C.; BAKKER, P.A.H.M. PIETERSE, C.M.J. Systemic resistance induced by rhizosphere bacteria. Annu. Rev. Phytopathol. 36:453-83. 1998.

VAN PEER, R., SCHIPPERS, B. Plant growth responses to bacterization and rhizosphere microbial development in hydroponic cultures. Can. J. Microbiol. 35:456-63. 1989.

VAN WEES, S.C.M.; PIETERSE, C.M.J.; TRIJSSENAAR, A.; VAN 'T WESTENDE, Y.A.M.; HARTOG, F.; VAN LOON, L.C. Differential induction of systemic resistance in Arabidopsis by biocontrol bacteria. Mol. Plant-Microbe Interact. 10:716-24. 1997.

VANDERPLANK, J. E. Disease resistance in plants. New York: Academic Press, 206 p. 1968. 